\title{
PATTERN OF POST BURN CONTRACTURE OF HAND IN EASTERN INDIA
}

\author{
Nishith M. Paul Ekka1, Pankaj Bodra², Shital Malua ${ }^{3}$
}

${ }^{1}$ Senior Resident, Department of Surgery, Rajendra Institute of Medical Sciences, Ranchi.

${ }^{2}$ Associate Professor, Department of Surgery, Rajendra Institute of Medical Sciences, Ranchi.

${ }^{3}$ Associate Professor, Department of Surgery, Rajendra Institute of Medical Sciences, Ranchi.

\begin{abstract}
BACKGROUND

Contracture of the hand poises great morbidity. Despite increasing sophistication in the overall management of acute thermal injuries, contractures still occur and are the most common cause of skin contracture in the hand. The problem of post burn contracture is largely preventable by good initial care. We studied 60 consecutive patients of post burn contracture of hand treated at Rajendra Institute of Medical Sciences, Ranchi, India with the aim to observe different patterns of post-traumatic contracture in hand and to assess the result of various treatment modalities.
\end{abstract}

\section{RESULTS}

Children and infants were most commonly involved with M:F ratio being 1.3:1. Flame burn was found to be the most common etiological factor. Right hand was involved in 53.33\% of cases. Fingers were the most common anatomical site involving $90 \%$ of patients followed by wrist and palm. Only $23.33 \%$ patients were initially treated by a specialist while majorities i.e. $46.67 \%$ were initially treated by quacks or paramedical personnel. Z-Plasty was used as a method of reconstruction in $50 \%$ of cases and was the most common surgical intervention used followed by V-Y plasty in $20 \%$ cases.

\section{CONCLUSION}

Major causes of neglect in the treatment of post burns contracture were illiteracy. Reconstructive procedures can greatly improve the function of the hands. Appropriate choice of procedures and timely surgery is the key for treatment.

\section{KEYWORDS}

Postburn Hand Deformity, Contracture Release, Hand Burns.

HOW TO CITE THIS ARTICLE: Ekka NMP, Bodra P, Malua S. Pattern of post burn contracture of hand in eastern India. J. Evolution Med. Dent. Sci. 2016;5(37):2217-2220, DOI: 10.14260/jemds/2016/515

\section{INTRODUCTION}

The human hand is one of the most sophisticated machines known to man. It has been assigned with a wide variety of functions to be performed. In a poor country like ours where most of the population depend on their hands to earn them bread, any limitation of function of hand causes great morbidity. Several functionally limiting sequelae can follow deep thermal injury to the hand.[1] Despite increasing sophistication in the overall management of acute thermal

These include release and insertion of skin graft or transposition flaps, this treatment is effective in restoring the movement of a joint, but the aesthetic result is not as pleasing. V-Y plasty, Z-plasty are other options. ${ }^{[3,4]}$ This study was conducted with the aim to observe different patterns of posttraumatic contracture in hand producing variable positional deformity and functional impairment and to assess the result of various treatment modalities in minimizing the effect of postburn contracture of hand.
\end{abstract} injuries, contractures still occur and are the most common cause of skin contracture in the hand.[2] The problem of post burn contracture is largely preventable by good initial care, which would include elevation of the hand, appropriate splinting, early grafting of deep burns and supervised physiotherapy.[3] Once contractures develop, correction of both functional and aesthetic deformities is indicated. While reconstructing a burnt hand, the burn surgeon must concentrate on restoring function than just on increasing the range of movement of individual joints. There are different treatment modalities in practice for the management of these contractures of hand depending upon their pattern.

Financial or Other, Competing Interest: None.

Submission 23-03-2016, Peer Review 19-04-2016,

Acceptance 25-04-2016, Published 07-05-2016.

Corresponding Author:

Dr. Nishith M. Paul Ekka,

Barhi Toli, Behind Indian Overseas Bank,

Purulia Road,

Ranchi-834001.

E-mail: drnmpekka@gmail.com

DOI: $10.14260 /$ jemds/2016/515

\section{PATIENT AND METHOD}

This is a cross sectional study, which was conducted from July, 2012 until April, 2015 at RIMS, Ranchi. The patients who visited Rajendra Institute of Medical Sciences, Ranchi for the treatment of post burn contractures of hand formed the pool for the present study. All the contractures involving limitation of movement by 60 degrees or more were only included in the present study. A detailed history was taken and clinical examination of the patients was carried out at the time of admission with special references to demographic characteristics, disease chronology, type of burn, severity of contracture etc. After admission type of surgery along with any complications were recorded. Patients were followed up for six months to see the overall outcome.

\section{RESULTS}

The total number of patients with post burn contracture during the study period was 60 . Out of them 64 were males $(56.67 \%)$ and 26 were females $(43.33 \%)$ with male-female ratio being 1.3: 1 . 
The age ranged between 1-52 years with the mean age of 20 years. The cohort was divided into 5 groups based on their age i.e 1-10,11-20, 21-30, 31-40, >40. Age group 1-10 was the one which was most commonly involved and constituted $40 \%$ of the cohort (24 of 60). Preschool children and adolescents staying at home were found to be most commonly affected $(33.3 \%)$, followed by students (30\%) and housewives $(23.33 \%)$, while crude and skilled manual workers were the ones least affected $(6.67 \%$ each).

Flame burn was found to be the most common etiological factor (56.67\%), followed by hot liquids (23.33\%), chemicals $(13.33 \%)$, while electrical burn $(3.33 \%)$ and burn due to hot objects (3.33\%) were the least in causing contractures. Right hand was involved in 32 cases (53.33\%), and was more commonly involved than the Left, $(n=20,33.33 \%)$, in 8 cases $(13.33 \%)$ both the hands were involved. Fingers were the most common anatomical site which were involved in 54 cases (90\%) while wrist is involved in 20 cases $(33.33 \%)$ and palm involved in 10 cases (16.66\%).

Most of the cases $(n=28,46.67 \%)$ were treated initially by quack or paramedical staff, while 18 cases $(30 \%)$ were treated by general practitioner. Only 14 cases $(23.33 \%)$ were treated by specialist. 30 cases (50\%) were treated by Z-plasty, out of this 10 cases were associated with skin grafting. Good results were observed in 22 cases, 8 cases showed fair results. In 20 (33.33\%) cases treatment given was contracture release by transverse incision followed by skin coverage in form of partial thickness skin graft in 10 cases, bipedical abdominal flap in 6 cases, groin flap in 2 case and bipedical abdominal flap along with partial-thickness skin graft in 2 case. 14 cases out of 20 had good results, 4 cases showed fair results and 2 cases had poor result. V-Y plasty has been done in 12 cases with good results in 6 cases, fair in 4 and poor result in 2 cases.

\begin{tabular}{|c|c|c|}
\hline Age in Years & No. of Cases & Percentage \\
\hline $0-10$ & 24 & 40 \\
\hline $11-20$ & 14 & 23.33 \\
\hline $21-30$ & 6 & 10 \\
\hline $31-40$ & 12 & 20 \\
\hline 41 \& above & 4 & 6.67 \\
\hline Total Table 1: Age Distribution \\
\hline \multicolumn{2}{|c|}{} \\
\hline
\end{tabular}

\begin{tabular}{|c|c|c|}
\hline Sex & No. of Cases & Percentage \\
\hline Male & 17 & 56.67 \\
\hline Female & 13 & 43.33 \\
\hline Total & $\mathbf{3 0}$ & \\
\hline \multicolumn{3}{|c|}{ Table 2: Gender Distribution } \\
\hline
\end{tabular}

\begin{tabular}{|c|c|c|}
\hline Occupation & No. of Cases & Percentage \\
\hline Student & 18 & 30 \\
\hline Housewife & 14 & 23.33 \\
\hline Crude manual worker & 4 & 6.67 \\
\hline Skilled manual worker & 4 & 6.67 \\
\hline Others & 20 & 33.33 \\
\hline Total & 60 & \\
\hline \multicolumn{3}{|c|}{ Table 3: Occupational Distribution } \\
\hline
\end{tabular}

\begin{tabular}{|c|c|c|}
\hline Mode & No. of Cases & Percentage \\
\hline Flame & 34 & 56.67 \\
\hline Hot liquids & 14 & 23.33 \\
\hline Hot object & 2 & 3.33 \\
\hline Chemical & 8 & 13.33 \\
\hline Electric & 2 & 3.33 \\
\hline \multicolumn{2}{|c|}{ Table 4: Mode of Initial Burn } \\
\hline
\end{tabular}

\begin{tabular}{|c|c|c|}
\hline Side of Contracture & No. of Cases & Percentage \\
\hline Right hand & 32 & 53.33 \\
\hline Left hand & 20 & 33.33 \\
\hline Both & 8 & 13.33 \\
\hline Total & $\mathbf{6 0}$ & \\
\hline \multicolumn{2}{|c|}{ Table 5: Side Involved } \\
\hline
\end{tabular}

\begin{tabular}{|c|c|c|}
\hline Type of Surgery & No. of Cases & Percentage \\
\hline Z-plasty & 20 & 33.33 \\
\hline Z-plasty with skin graft & 10 & 13.33 \\
\hline V-y advancement & 12 & 20 \\
\hline Partial thickness skin graft & 10 & 16.67 \\
\hline Bipedical abdominal flap & 6 & 10 \\
\hline Groin flap & 2 & 3.33 \\
\hline $\begin{array}{c}\text { Bipedical abdominal flap } \\
\text { with partial thickness skin } \\
\text { graft }\end{array}$ & 2 & 3.33 \\
\hline Total & 60 & \\
\hline \multicolumn{3}{|c|}{ Table 6: Treatment Given } \\
\hline
\end{tabular}

\begin{tabular}{|c|c|c|c|c|}
\hline $\begin{array}{c}\text { Treatment } \\
\text { Modality }\end{array}$ & No. of Cases & Good & Fair & Poor \\
\hline Z-plasty & 20 & 14 & 6 & 0 \\
\hline $\begin{array}{c}\text { Z-plasty with skin } \\
\text { graft }\end{array}$ & 10 & 8 & 2 & 0 \\
\hline $\begin{array}{c}\text { V-y plasty } \\
\text { Transverse } \\
\text { incision \& } \\
\text { Partial thickness } \\
\text { skin graft }\end{array}$ & 12 & 6 & 4 & 2 \\
\hline $\begin{array}{c}\text { Transverse } \\
\text { incision \& } \\
\text { Bipedical } \\
\text { abdominal flap }\end{array}$ & 6 & 4 & 2 & 0 \\
\hline $\begin{array}{c}\text { Transverse } \\
\text { incision \& } \\
\text { Groin flap }\end{array}$ & 2 & 2 & 0 & 0 \\
\hline $\begin{array}{c}\text { Transverse } \\
\text { incision \& } \\
\text { Bipedical } \\
\text { abdominal flap } \\
\text { with partial } \\
\text { thickness skin } \\
\text { graft }\end{array}$ & 2 & 2 & 0 & 0 \\
\hline Total & $\mathbf{6 0}$ & $\mathbf{4 0}$ & $\mathbf{1 6}$ & $\mathbf{4}$ \\
\hline \multicolumn{2}{|c|}{ Table 7: Result of Treatment } & \\
\hline
\end{tabular}




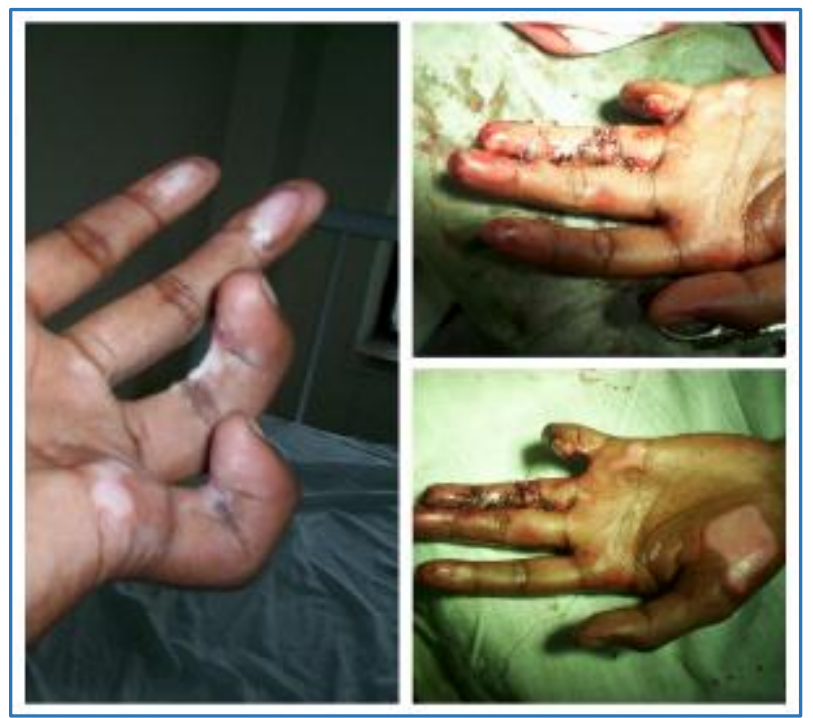

Fig. 1: PBC of Ring and Little Finger Treated by Z-Plasty and Skin Grafting

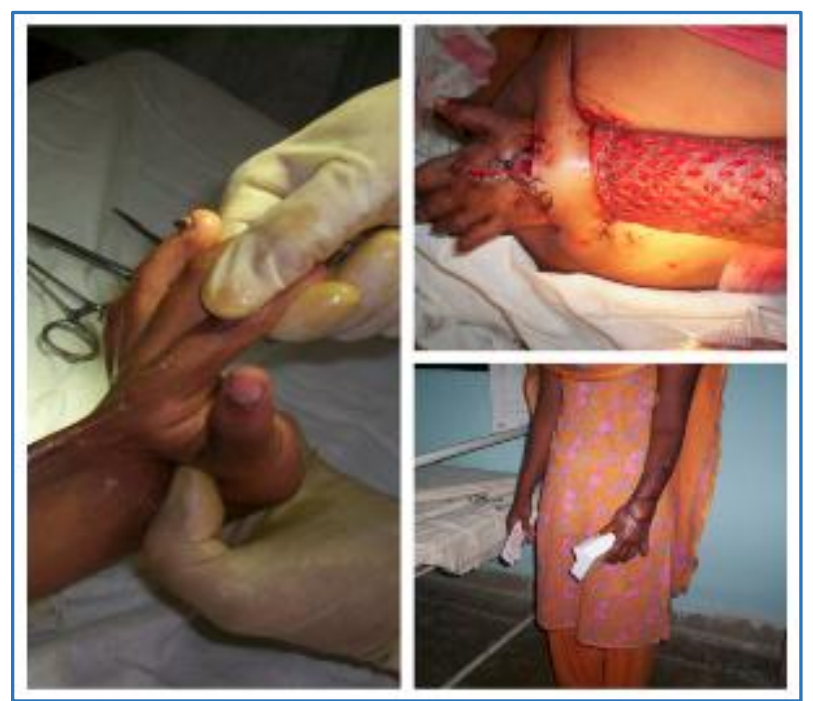

Fig. 2: Extensor Contracture of Wrist Treated by Bipedical Flap and Split Thickness Skin Graft

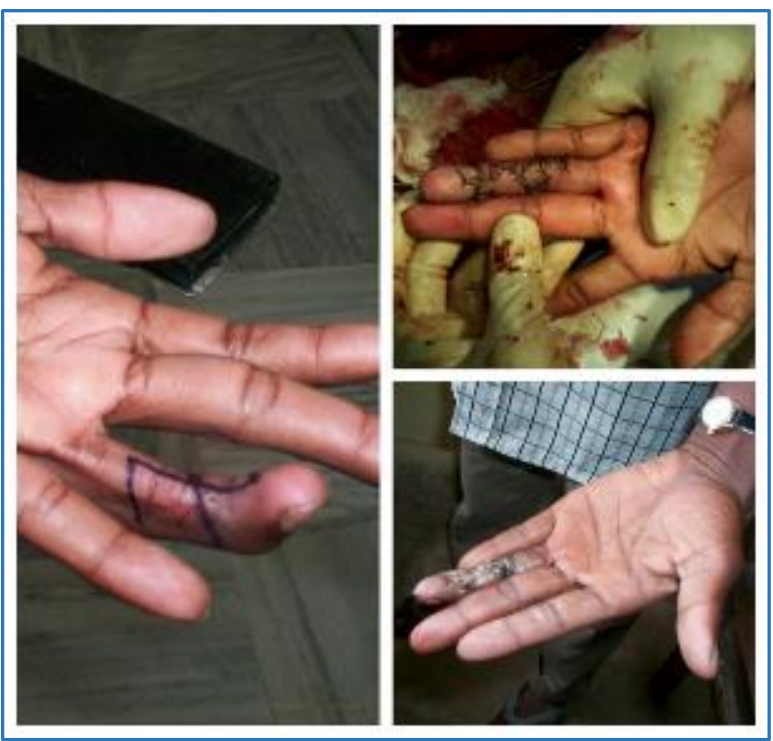

Fig. 3: PBC Involving Ring Finger Treated by Multiple Z Plasty
In the present study the majority of cases falls in the group of 0 -10 years i.e. 24 out of $60(40 \%)$ and only 4 cases fell under the age group of 41 years and above. It was observed that the age group of $11-20$ \& 31-40 claimed $7 \& 6$ cases $(23.33-20 \%)$ respectively and stood at second and third place.

Ogbonna et al (1984) in their study of 52 cases have observed $52 \%$ of cases to be under five years. They didn't find any case above 41 years. [5] Muguti GI et al in their review of 53 patients observed that $85 \%$ were aged 12 years or less. ${ }^{[6]}$ Van Niekerk A et al in their study of 1201 patients saw that burn injury incidence is particularly high for toddlers and infants. ${ }^{[7]}$ This may be due to the fact that children in their curiosity to explore the newly found world mostly ignore the dangers involved and fall easy victims to accidents. Also that these patients do not comply with advise, primary physiotherapy and maintain the position of comfort, thus resulting in contracture development.

Out of 60 patients in this series $56.67 \%$ were male and $43.33 \%$ female, with male-female ratio being 1.3:1. The age ranged between 1-52 years with the mean age of 20 years. Ogbonna et al (1984) observed that out of 52 cases 32 i.e. 61.5 $\%$ were male and 20 cases i.e. $38.46 \%$ were females. Gupta RK et al (2014) in their study also observed male female ratio of 1.03.[8] Our study is in concordance with the other studies. The preponderance of males over females may be due to the fact that males whether children or adults are more adventurous and more prone to injury and also that they are the bread earners of the family and thus morbidity affecting them is taken seriously and medical care is sorted, while the females are ignored. Most of the patients i.e. 20 cases (33.33\%) were either children not going to school or adolescents staying at home. Others were students $30 \%$, housewives $23.33 \%$, crude and skilled manual workers $6.67 \%$ each. Gupta RK et al (2014) in their study observed that $72.13 \%$ children either never went to school or were drop outs.[8] These figures point out that improvement of socio-economic status and provisions of a good education will do a lot to safeguard against these disabling injuries. The lower percentage of crude and skilled manual workers may be because they are the bread earners in the family and their disability will affect the whole family thus they are prompt to receive early treatment and follow advice.

In our series $50 \%$ of cases were due to flame burn. The least number of cases were due to scald and electrical burn i.e. $3.33 \%$ each. Ogbonna et al (1984) in his study of 52 cases observed open fire burns 9 cases chemical burn in 3 cases and inflammable liquid in 11 cases. Zamboni et al in their study of 92 paediatric hand burn observed that scald burns (49\%) were most common mode of injury, followed by flame (34\%).[9] M. Saaiq et al in their study of 174 cases found that $81.69 \%$ were due to flame burn. ${ }^{[4]}$ The fact that maximum number of cases are due to open fire is that fire is used by our population for almost everything. May it be cooking, which is done by a majority by open fire, or for rituals or to warm them up in winter or as a source of light. Also that dressing in our country is loose for example "Sari" and liable to catch fire easily.

In our series right hand was involved in $53.33 \%$ of cases while left hand was involved in $33.33 \%$ of cases, in $13.33 \%$ both hands were involved. Gupta RK et al. ${ }^{[8]}$ in their study also found that right hand was more commonly involved (60.65\%). It is quite natural, since most of the people are right-handed and thus it has a greater chance of injury and thus contracture. 
Fingers were seen to be most commonly affected in our series i.e. 53.33\% followed by palm. Ogbonna et al (1984) observed that $50 \%$ of the hand contractures involved the fingers. ${ }^{[5]}$ Bhattacharya et al (1984) observed in their study of 50 patients that $56 \%$ of cases were of hand, with a majority involving fingers.[10] Since fingers are involved in any work done by the hand and are the part of hand that is most prone to injuries and thus and contractures. Most of the cases ( $n=28,46.67 \%$ ) were treated initially by quack or paramedical staff, while $30 \%$ were treated by general practitioner and only $23.33 \%$ cases were treated by a specialist. Sabapathy S.R were of the opinion that the problem of post burn contracture is largely preventable by good initial care, which would include elevation of the hand, appropriate splinting, early grafting of deep burns and supervised physiotherapy.[3] Some authors.[1] have observed that despite appropriate initial management, contractures are common. In our opinion initial treatment by experts in form of splinting, skin grafting and exercise may prevent contracture development.

30 cases $(50 \%)$ were treated by Z-plasty which was the most commonly used method, out of this 10 cases were associated with skin grafting. Good results were observed in 22 cases, 8 cases showed fair results. In 20 cases treatment given was contracture release by transverse incision followed by skin coverage in form of partial thickness skin graft in 10 cases, bipedical abdominal flap in 6 cases, groin flap in 2 case and bipedical abdominal flap along with partial-thickness skin graft in 2 case. 14 cases out of 20 had good results, 4 cases showed fair results and 2 cases had poor result. V-Y plasty has been done in 12 cases with good results in 6 cases, fair in 4 and poor result in 2 cases. A number of methods using basic reconstructive techniques have been proposed which include contracture release and grafting, cross finger flaps, side finger flaps, Z-plasty, V-Y advancement flaps and local advancement flaps.[3] Fufa et al in their study concluded that the mainstays of management of these contractures include complete surgical excision of scar tissue and resurfacing of the resultant soft tissue defect, most commonly with full-thickness skin grafts. If scar contracture release results in major exposure of the tendons or joints, distant tissue transfer may be required.[1] Peker $F$ et al used a combination of $Y-V$ advancement and Z-plasty to improve the release of linear flexion contractures of the fingers and achieved good results.[11] M. Saaiq et al in their study observed that various procedures employed alone or in combination included contracture release with skin grafting, Z-plasties, supraclavicular artery flaps, abdominal flaps and posterior interosseous artery flap.[4] Ulkür $\mathrm{E}$ et al concluded that proximal interphalangeal joint can be released by transverse incision and ample resection of scarred tissue, and the resulting palmar skin defect that cannot be covered by using the finger's own flaps or cross-finger flap can be covered by combined use of cross-finger and side-finger transposition flaps.[12]

\section{CONCLUSION}

Major causes of neglect in the treatment of post burns contracture were illiteracy, poverty and lack of awareness. Children in their ignorance of danger are mostly affected. Flame burn was the leading cause of post burn contracture and specialized initial treatment resulted in better functional outcome. Z- Plasty is apparently a good modality in treating hand contractures.

Reconstructive procedures can greatly improve the function of the hands. Appropriate choice of procedures and timely surgery is the key for treatment of these patients.

\section{REFERENCES}

1. Fufa DT, Chuang SS, Yang JY. Post burn contractures of the hand. Journal of Hand Surgery 2014;39(9):1869-76.

2. Kurtzman LC, Stern PJ. Upper extremity burn contractures. Hand Clinics 1990;6(2):261-79.

3. Sabapathy SR, Bajantri B, Bharathi RR. Management of post burn hand deformities. Indian J Plast Surg 2010;43:S72S79.

4. Saaiq M, Zaib S, Ahmad S. The menace of post-burn contractures: a developing country's perspective. Ann Burns Fire Disasters 2012;25(3):152-8.

5. Ogbonna C, Ofodile FA. Post-burn contractures in Ibadan. Trop Doct 1984;14(3):122-4.

6. Muguti GI, Fleming AN. Contractures after burns: some observations from a 3-year review in Zimbabwe. J R Coll Surg Edinb 1992;37(3):187-90.

7. Van Niekerk A, Rode H, Laflamme L. Incidence and patterns of childhood burn injuries in the western Cape, South Africa. Burns 2004;30(4):341-7.

8. Gupta RK, Jindal N, Kamboj K. Neglected post burns contracture of hand in children: analysis of contributory socio-cultural factors and the impact of neglect on outcome. J Clin Orthop Trauma 2014;5(4):215-20.

9. Zamboni WA, Cassidy M, Eriksson E. Hand burns in children under 5 years of age. Burns Incl Therm Inj 1987;13(6):476-83.

10. Bhattacharya V, Singh KP, Sinha JK, et al. Macroradiographic study of post-burn contracture of limbs. Burns 1984;10(5):374-7.

11. Peker F, Celebiler O. Y-V advancement with Z-plasty: an effective combined model for the release of post-burn flexion contractures of the fingers. Burns 2003;29 (5):47982.

12. Ulkür E, Acikel C, Karagoz H, et al. Treatment of severely contracted fingers with combined use of cross-finger and side finger transposition flaps. Plast Reconstr Surg 2005;116(6):1709-14. 